\title{
Pemisahan Timbal (Pb) dalam Galena dengan Metode Flotasi Menggunakan Deterjen
}

\author{
Nora Idiawati ${ }^{1 *}$, Annisa Triantie ${ }^{1)}$, Nelly Wahyuni ${ }^{1)}$ \\ 1)Program Studi Kimia, Fakultas MIPA, Universitas Tanjungpura, \\ Jl. Prof. Dr. H. Hadari Nawawi, Pontianak \\ *Email : noraidiawati_srg@yahoo.co.id
}

\begin{abstract}
Abstrak
Metode flotasi dan xanthate sebagai zat kolektor telah banyak digunakan untuk memisahkan logamlogam tertentu dalam suatu campuran. Pada penelitian ini digunakan deterjen sebagai pengganti xanthate untuk memisahkan timbal dalam galena. Proses flotasi dilakukan dengan variasi massa deterjen yaitu 5 , 10, 15, dan 20 gram dan dilakukan dengan variasi waktu flotasi yaitu 1, 3, 6, dan 10 jam. Kadar timbal hasil pemisahan tersebut dianalisis dengan metode gravimetri. Proses flotasi dapat meningkatkan kemampuan deterjen sebagai zat kolektor untuk memisahkan timbal sebesar 11\%. Konsentrasi optimum deterjen sebagai zat kolektor untuk pemisahan timbal dalam galena dengan massa sampel 5 gram menggunakan metode flotasi adalah 15 gram dengan waktu optimum 6 jam diperoleh kadar timbal hasil pemisahan sebesar 71\%.
\end{abstract}

Kata Kunci : Galena, timbal, flotasi, deterjen, zat kolektor

\section{Latar Belakang}

Galena (Gambar 1) merupakan sejenis batuan yang memiliki komposisi sebagian besar logam timbal $(\mathrm{Pb})$ dan logam seng $(\mathrm{Zn})$. Kedua logam ini ditemukan di alam dalam bentuk bijih timbal $(\mathrm{PbS})$ dan bijih sphalerite $(\mathrm{ZnS})$ yang memiliki kadar yang berbeda. Logam timbal $(\mathrm{Pb})$ banyak dimanfaatkan oleh sebagian besar industri misalnya industri baterai, plumbing dan minyak.

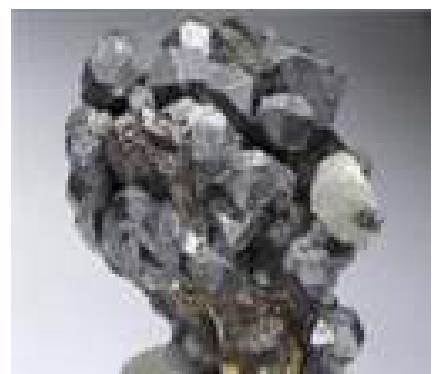

Gambar 1. Galena (Yudiarto, 2008)

Salah satu metode untuk memisahkan timbal adalah flotasi. Flotasi merupakan metode fisika kimia untuk memisahkan mineral dengan memanfaatkan sifat permukaan mineral yaitu sifat hidrofilik dan hidrofobiknya (Rahayu, 2002). Pada proses flotasi diperlukan bahan kimia tambahan berupa zat kolektor. Kolektor merupakan reagen yang memiliki permukaan selektif, karena mempunyai gugus hidrofobik dan hidrofilik. Salah satu bahan kimia yang dapat digunakan sebagai zat kolektor adalah bahan kimia yang mengandung surfaktan seperti deterjen. Selain lebih ekonomis, deterjen memiliki kemampuan seperti zat kolektor yaitu dapat mengubah sifat kompleks ion dari hidrofilik menjadi hidrofobik. Selain itu deterjen dapat juga berfungsi sebagai pembuih. Oleh karena itu, metode flotasi dianggap lebih murah dan mudah.

Pada penelitian ini dilakukan pemisahan timbal dalam galena dengan metode flotasi menggunakan deterjen sebagai zat kolektor. Penelitian ini bertujuan untuk mengetahui kinerja deterjen sebagai zat kolektor pada proses pemisahan timbal dalam galena dengan metode flotasi pada variasi massa deterjen dan variasi waktu flotasi. Hasil penelitian ini diharapkan dapat meningkatkan nilai ekonomis dari batu galena menjadi sumber timbal dalam skala laboratorium.

\section{Metodologi}

Pengambilan sampel dilakukan pada satu lokasi di daerah Monterado, Kabupaten Bengkayang, Kalimantan Barat. Sampel diambil menggunakan palu tambang dan disimpan menggunakan plastik polietilen dan segera dibawa ke laboratorium.

Sampel dikeringkan agar terbebas dari kandungan air. Setelah kering sampel dicampur menjadi satu. Campuran ini kemudian digerus menjadi partikel yang lebih kecil dan diayak 
menggunakan ayakan 200 mesh. Sampel yang telah digerus ditimbang sebanyak 50 gram untuk perlakuan selanjutnya dan dihitung kadar airnya (ISO 4296/1, 1984)

Ekstraksi timbal dari batu galena dengan cara sampel ditimbang 5 gram dan deterjen dengan variasi massa yaitu 5, 10, 15, dan 20 gram. Sampel dan deterjen pada masing-masing konsentrasi dilarutkan dalam 1 Liter akuades. Campuran diaduk menggunakan stirer dan kompresor penghasil gelembung dengan variasi waktu 1, 3, 6, 8, dan 10 jam. Hasil ekstraksi dianalisis kadar timbalnya. Dilakukan perlakuan yang sama untuk variasi massa deterjen yang berbeda dengan massa sampel yang sama dan dilakukan triplo.

Analisis kadar timbal dengan cara sampel ditimbang masing-masing sebanyak 2 gram. Diencerkan menggunakan aquades sebanyak $150 \mathrm{~mL}$ dan dikocok menggunakan stirrer. Ditambahkan asam asetat p.a sebanyak $5 \mathrm{~mL}$ sampai reaksi asam, diukur menggunakan $\mathrm{pH}$ meter. Dipanaskan sampai mendidih dan diaduk selama 10 menit. Ditambahkan $10 \mathrm{~mL} \mathrm{~K}_{2} \mathrm{CrO}_{4}$ dan dididihkan selama 10 menit hingga endapan menurun. Didinginkan dan disaring. Endapan dicuci menggunakan akuades panas. Residu dioven selama 1 jam pada suhu $120^{\circ} \mathrm{C}$ dan ditimbang (ISO 4296/1, 1984).

Analisis kadar zink dengan cara sampel ditimbang sebanyak 0,25 gram. Diencerkan dengan aquades sampai volume menjadi 100 mL. Dimasukkan dalam erlenmeyer dan ditambahkan 1-2 tetes indikator metal merah dan dinetralkan dengan larutan ammonia 1:1 (sampai berwarna jingga). Dipanaskan hingga mendidih. Ditambahkan $10 \mathrm{~mL}$ larutan diammonium hidrogen posfat $10 \%$ dan diaduk hingga terbentuk endapan. Dipanaskan menggunakan penangas air selama 30-60 menit. Didiamkan dan disaring. Dicuci dengan diammonium hidrogen posfat $1 \%$ dan dengan aquades dingin. Dimasukkan dalam oven selama 1 jam pada suhu $100-105^{\circ} \mathrm{C}$ dan ditimbang (ISO 4296/1, 1984).

Analisis kadar besi dengan cara sampel 0,9 gram galena dimasukkan ke dalam beaker. Ditambahkan aquades $50 \mathrm{~mL}$ dan diaduk. Ditambahkan $10 \mathrm{~mL} \mathrm{HCl}$ 1:1 dan 1-2 ml $\mathrm{HNO}_{3}$ pekat. Dipanaskan sampai mendidih hingga warna menjadi kuning. Diencerkan dengan aquades hingga volume $200 \mathrm{~mL}$, dididihkan dan ditambahkan perlahan-lahan larutan $\mathrm{NH}_{4} \mathrm{OH}$ 1:1 agak berlebih hingga uap berbau $\mathrm{NH}_{4} \mathrm{OH}$. Dididihkan selama 1 menit dan disimpan sampai endapan turun. Disaring dengan kertas saring tanpa abu. Dicuci dengan aquades. Dimasukkan ke dalam kurs porselen dan ditanur selama 15 menit pada suhu $1000^{\circ} \mathrm{C}$. Didinginkan dalam desikator dan ditimbang (ISO 4296/1, 1984).

\section{Hasil dan Pembahasan}

Pada proses flotasi dihasilkan yang berfungsi untuk mengikat senyawa logam-logam yang bersifat hidrofobik untuk diapungkan sehingga dapat dipisahkan dari senyawa logamlogam yang bersifat hidrofilik. Timbal terdiri dari ion yang mempunyai permukaan hidrofilik, sehingga partikel tersebut dapat diikat oleh air. Sedangkan senyawa logam-logam lain misalnya Zn yang terikat molekul air akan terlepas dan akan berubah menjadi hidrofobik dengan menambahkan zat kolektor yaitu deterjen, sehingga ujung molekul hidrofobik dari deterjen akan terikat molekul hidrofobik dari gelembung dan Zn dapat diapungkan.

Interaksi Zn dengan gelembung udara akan semakin maksimal dengan adanya senyawa surfaktan LAS. Surfaktan LAS yang terdapat di dalam deterjen akan menurunkan tegangan antar muka air dengan gelembung udara sehingga interaksi $\mathrm{Zn}$ dengan gelembung udara semakin kuat. Zn tersebut kemudian dipisahkan ke permukaan oleh gelembung udara. Proses interaksi antara $\mathrm{Zn}$ dengan gelembung udara berdasarkan asas polaritas, dimana Zn yang mempunyai sifat hidrofobik pada molekulnya akan stabil pada gelembung udara yang kemudian bergerak ke permukaan pada saat proses flotasi.

Pengaruh waktu flotasi dan massa deterjen terhadap kinerja proses pemisahan timbal dalam galena dapat dilihat pada Gambar 2. Pada Gambar 2 menunjukkan adanya kenaikan yang cukup signifikan dari persentase timbal yang diekstraksi dari galena. Kenaikan persentase yang paling tinggi terdapat pada waktu flotasi 6 jam dengan variasi massa deterjen 15 dan 20 gram dengan persentase timbal sebesar $71 \%$. Kenaikan persentase timbal ini disebabkan karena lamanya waktu kontak yang memberikan waktu lebih banyak untuk membentuk flok pada saat proses flotasi sehingga pemisahan semakin baik sampai batas waktu optimumnya dan disertai dengan penambahan variasi massa deterjen.

Waktu kontak merupakan salah satu parameter yang penting dalam proses flotasi. Waktu berkaitan dengan laju reaksi dimana dinyatakan sebagai perubahan konsentrasi senyawa terhadap waktu. Waktu kontak menunjukkan waktu yang dibutuhkan agar kesetimbangan flotasi tercapai dan dapat diketahui kemampuan maksimal deterjen untuk memisahkan timbal dalam galena (Karamah et al., 2008). 


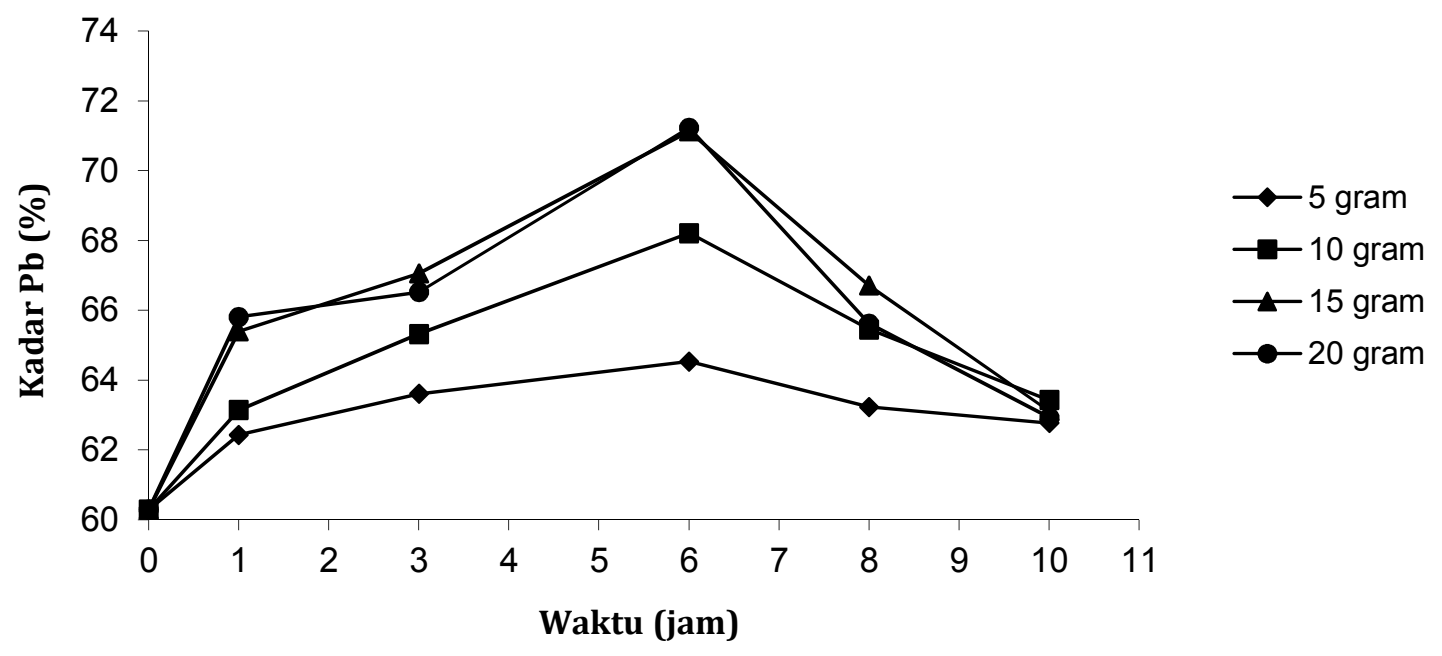

Gambar 2. Pengaruh waktu flotasi dan massa deterjen terhadap persentase timbal yang diekstraksi dari galena

Penurunan persentase timbal yang diekstraksi dari galena terjadi pada waktu flotasi 8 dan 10 jam dengan variasi massa 5, 10, 15, dan 20 gram. Hal ini diakibatkan pada proses flotasi terjadi kejenuhan akibat kelebihan konsentrasi deterjen sehingga partikel-partikel yang akan dipisahkan telah mengalami batas optimum pemisahan dan tidak ada lagi partikelpartikel yang dapat dipisahkan meskipun dilakukan penambahan konsentrasi deterjen dan penambahan waktu flotasi. Penentuan konsentrasi optimum dan waktu optimum flotasi untuk pemisahan timbal dalam galena dapat ditentukan dengan uji statistik menggunakan uji ANOVA.

Pengaruh massa deterjen terhadap persentase timbal yang diekstraksi dari galena dilakukan dengan metode flotasi pada masingmasing sampel dengan variasi massa deterjen 5 , 10 , 15, dan 20 gram pada kondisi yang sama dengan variasi waktu flotasi $1,3,6,8$, dan 10 jam.

Pada Gambar 2 terlihat pada variasi massa deterjen 5, 10, dan 15 gram mengalami kenaikan persentase yang dihasilkan. Menurut Karamah et al., (2008) kenaikan persentase ini disebabkan karena semakin banyaknya flok yang terbentuk akibat penambahan surfaktan dari deterjen, sehingga semakin banyak pula logam-logam yang memiliki massa jenis lebih kecil dan bersifat lebih hidrofobik dibandingkan dengan timbal yang dapat terangkat ke permukaan bersama gelembung-gelembung udara dari busa yang dihasilkan dan terpisah.

Kadar pemisahan timbal pada Gambar 2 mengalami penurunan pesentase pada massa deterjen 20 gram dengan variasi waktu flotasi. Penurunan ini terjadi karena konsentrasi deterjen sudah melewati konsentrasi misel kritik (KMK). Menurut Tolls et al., (1997) nilai KMK untuk surfaktan LAS adalah $16 \mathrm{~g} / \mathrm{L}$. Hal ini yang menyebabkan proses flotasi dengan massa deterjen 20 gram dalam 1 liter aquades tidak mengalami peningkatan kadar timbal karena melewati nilai KMK. Konsentrasi misel kritik (KMK) adalah konsentrasi dimana surfaktan mulai terbentuk misel. Misel merupakan kumpulan sejumlah molekulmolekul surfaktan yang membentuk partikel ukuran koloid sehingga mengganggu proses pembentukan gelembung udara. Misel terbentuk dalam larutan zat aktif permukaan di atas konsentrasi tertentu yang disebut konsentrasi misel kritik (KMK). Saat misel terbentuk bagian ekor dari surfaktan berada pada posisi di dalam sedangkan bagian kepala berada pada posisi di luar (Gambar 3)

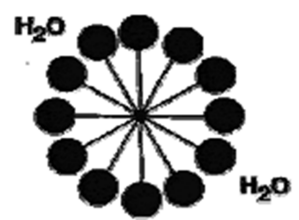

Gambar 3. Struktur misel pada konsentrasi misel kritik dalam medium air

Proses terbentuknya misel terjadi pada saat di bawah konsentrasi misel kritik, amfifil (surfaktan yang memiliki bagian hidrofilik dan hidrofobik) yang mengalami adsorpsi pada antar muka udara atau air meningkat saat konsentrasi amfifil dinaikkan, sehingga dapat dicapai suatu titik dimana antar muka dan fase keduanya menjadi jenuh dengan monomer (kondisi KMK). Setiap penambahan amfifil yang melebihi konsentrasi akan mengagregasi 
membentuk misel. Amfifil di dalam air mempunyai rantai hidrokarbon yang menghadap ke misel. Bagian-bagian hidrofilik dari amfifil mengelilingi inti hidrokarbon dan terikat dengan molekul-molekul air.

Surfaktan dapat membentuk misel monolayer atau bilayer tergantung konsentrasi surfaktan. Menurut Sullivan et al., (2007) dan Jean and Louis (1994), di bawah konsentrasi misel kritik (KMK) akan terbentuk misel monolayer dan di atas KMK akan terbentuk misel bilayer. Pada konsentrasi yang rendah, surfaktan mempunyai kemampuan yang rendah untuk terikat pada permukaan (Loong, 2004). Pada KMK, molekul surfaktan menutup seluruh permukaan. Di atas KMK, peningkatan konsentrasi surfaktan secara kontinu menurunkan tegangan antarmuka sampai misel terbentuk dan menyebabkan pembentukan bilayer (Carr and Shantz, 2005 ; Jean and Louis, 1994).

Proses flotasi pemisahan timbal dalam galena dipengaruhi juga dari banyaknya gelembung udara untuk mengangkat partikelpartikel yang memiliki massa jenis lebih kecil dari timbal. Jika misel yang terbentuk semakin banyak maka semakin menurun pula kinerja surfaktan dalam membentuk gelembung udara. Hal ini menyebabkan proses flotasi juga akan terganggu sehingga terjadilah penurunan persentase pemisahan timbal dalam galena (Sabariman, 2004 ; Karamah et al., 2008).

Penentuan konsentrasi optimum dengan menggunakan uji ANOVA bertujuan untuk melihat besarnya konsentrasi optimal deterjen pada proses flotasi pemisahan timbal dalam galena. Uji statistik dilakukan untuk mengetahui apakah terdapat perbedaan yang signifikan dalam peningkatan persentase pemisahan timbal yang diekstraksi dari galena. Dalam pengujian ini dilakukan uji pada waktu 6 jam, karena pada Gambar 2 terlihat kenaikan persentase timbal untuk variasi massa deterjen paling banyak terdapat pada waktu tersebut.

Uji ini menggunakan tingkat signifikan 0,05 $(\alpha=5 \%)$ yang berarti tingkat kepercayaan untuk uji ini sebesar 95\%. Hipotesis yang digunakan adalah Ho (tidak ada perbedaan antara rata-rata persentase timbal yang diekstraksi dari galena tiap variasi massa deterjen) dan $\mathrm{Ha}$ (ada perbedaan antara rata-rata persentase timbal yang diekstraksi dari galena tiap variasi massa deterjen).

Berdasarkan uji ANOVA pada masingmasing parameter, dilihat bahwa $\mathrm{F}$ hitung lebih besar dari $\mathrm{F}$ tabel. Hal ini berarti Ho ditolak dan Ha diterima, sehingga dapat disimpulkan bahwa ada perbedaan antara rata-rata persentase timbal yang diekstraksi dari galena tiap variasi massa deterjen yang digunakan. Hal ini diperkuat dengan post hoct test dimana terdapat tanda bintang $\left(^{*}\right.$ ) pada massa deterjen 15 gram dengan massa lainnya yang berarti persentase timbal yang diekstraksi dari galena berbeda signifikan dengan persentase timbal yang diekstraksi dari galena dengan massa deterjen lainnya. Berdasarkan dari grafik dan uji statistik dapat disimpulkan bahwa massa deterjen 15 gram merupakan konsentrasi optimum untuk proses pemisahan timbal dalam galena. Sehingga untuk proses flotasi, sampel akan dipisahkan dengan massa deterjen 15 gram.

Penentuan waktu optimum flotasi dengan menggunakan uji ANOVA bertujuan untuk melihat waktu optimal pada proses flotasi pemisahan timbal dalam galena. Uji statistik dilakukan untuk mengetahui apakah terdapat perbedaan yang signifikan dalam peningkatan persentase timbal yang diekstraksi dari galena. Dalam pengujian ini dilakukan uji pada massa deterjen 15 gram, karena pada Gambar 4.1 terlihat kenaikan persentase pemisahan timbal untuk variasi waktu paling banyak terdapat pada konsentrasi ini. Selain itu sudah ditentukan penentuan konsentrasi optimum, dimana diperoleh massa deterjen optimum adalah 15 gram.

Uji ini menggunakan tingkat signifikan 0,05 $(\alpha=5 \%)$ yang berarti tingkat kepercayaan untuk uji ini sebesar 95\%. Hipotesis yang digunakan adalah Ho (tidak ada perbedaan antara rata-rata persentase timbal yang diekstraksi dari galena tiap variasi waktu flotasi) dan $\mathrm{Ha}$ (ada perbedaan antara rata-rata persentase timbal yang diekstraksi dari galena tiap variasi waktu flotasi).

Berdasarkan uji ANOVA pada masingmasing parameter, dilihat bahwa $\mathrm{F}$ hitung lebih besar dari F tabel. Hal ini berarti Ho ditolak dan Ha diterima, sehingga dapat disimpulkan bahwa ada perbedaan antara rata-rata persentase timbal yang diekstraksi dari galena tiap variasi waktu flotasi yang digunakan. Hal ini diperkuat dengan post hoct test dimana terdapat tanda bintang $\left(^{*}\right)$ pada waktu 6 jam dengan waktu lainnya yang berarti persentase timbal yang diekstraksi dari galena berbeda signifikan dengan persentase timbal yang diekstraksi dari galena dengan waktu flotasi lainnya. Berdasarkan dari grafik dan uji statistik dapat disimpulkan bahwa waktu flotasi 6 jam merupakan waktu optimum untuk proses flotasi pemisahan logam timbal dalam galena. 


\section{Kesimpulan}

Berdasarkan hasil yang diperoleh dalam penelitian ini, dapat diambil kesimpulan sebagai berikut:

1. Pemisahan timbal dalam galena dapat dilakukan menggunakan metode flotasi dengan deterjen sebagai zat kolektor.

2. Konsentrasi optimal deterjen sebagai zat kolektor untuk pemisahan timbal dalam galena adalah 15 gram dengan waktu optimal 6 jam yang menghasilkan peningkatan kadar timbal sebesar $11 \%$, dengan kadar awal sebelum flotasi sebesar $60 \%$ meningkat menjadi $71 \%$ setelah diflotasi.

\section{Daftar Pustaka}

Carr, S., and Shantz, D., 2005, Non-IonicMicroemulsion Mediated Growth of Zeolite A, Elsevier, Micro and Meso. Mater., 85 : 284-292.

ISO (International Standard Operation) 4296/1, 1984, Manganese Ore Sampling, Part 1 : Increment Sampling, First Edition, Switzerland.

Jean and Louis, 1994, Interfacial Phenomena in Dispersed Systems, Laboratory of Formulation, Interfaces Rheology and Processes, Merida-Venezuela.

Karamah, E.F., Bismo, S., 2008, Pengaruh Dosis Koagulan PAC dan Surfaktan SLS Terhadap Kinerja Proses Pengolahan Limbah Cair yang Mengandung Logam Besi (Fe), Tembaga (Cu) dan Nikel (Ni) dengan Flotasi Ozon, Prosiding Seminar Nasional Rekayasa Kimia dan Proses, Departemen Teknik Kimia, Universitas Indonesia, Depok.

Sabariman., 2004, Pemanfaatan Tailing Proses Flotasi Bijih Timbal Menjadi Konsentrat $\mathrm{Pb}$ sebagai Bahan Baku Utama Logam $\mathrm{Pb}$, Wawasan Tridharma No. 4.

Sullivan, Hunter, Bowman, 1997, Topological and Thermal Properties of SurfactantModified Clinoptilolite Studied by TappingMode-Atomic Force Microscopy and HighResolution Thermogravimetric Analysis, clays and clay min., 45(1) : 42-53, Aiken, South Carolina.

Tolls J, Haller M, DeGraaf I., 1997, Bioconcentration of LAS: Experimental Determination and Extrapolation to Environmental mixtures. Environ Sci Technol 31 (12): 3426-3431.

Yudiarto, A., 2008, Proses Ekstraksi Pb dan Zn dari Bijih Galena (PbS) dan Sphalerite (ZnS), Jakarta. 